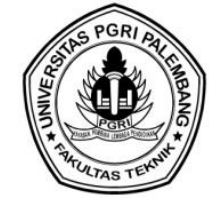

\title{
EVALUASI INSTALASI PENGOLAHAN AIR LINDI DI TEMPAT PEMBUANGAN AKHIR SAMPAH (TPAS) SIMPANG KANDIS KABUPATEN OGAN KOMERING ULU
}

\author{
Enda Kartika Sari", Lucyana \\ Prodi Teknik Sipil, Fakultas Teknik dan Komputer, Universitas Baturaja \\ *Corresponding Author, email: endaunbara@gmail.com
}

\begin{abstract}
ABSTRAK
Air lindi merupakan air dengan konsentrasi kandungan organik yang tinggi, terbentuk dalam landfill akibat adanya air hujan yang masuk. Cairan ini sangat berbahaya karena selain kandungan organiknya tinggi, juga mengandung unsur logam (seperti $\mathrm{Zn}$, $\mathrm{Hg}$ ). Setiap hari volume sampah yang dihasilkan di Kabupaten Ogan Komering Ulu mencapai sekitar $180 \mathrm{~m}^{3}$ perhari atau sampah mencapai 50 ton/harinya. Air lindi yang dihasilkan di bak penambungan semakin banyak dan berlimpah apalagi bila hujan terjadi terus menerus. Semakin bertambahnya timbunan sampah setiap harinya akan mempengaruhi kinerja instalasi saluran air lindi, dan berpengaruh terhadap penampungan debit air lindi yang dihasilkan dari TPAS Simpang Kandis Kabupaten Ogan Komering Ulu. Tujuan penelitian adalah untuk mengevaluasi instalasi pengolahan air lindi di TPAS Simpang Kandis Kabupaten Ogan Komering Ulu. Pengolahan dan analisis data yang dilakukan adalah menghitung besarnya debit lindi yang dihasilkan dari TPAS Simpang Kandis, dengan melakukan pengukuran secara langsung serta melakukan perhitungan debit lindi dengan metode rasional, mengevaluasi kondisi instalasi pengolah lindi eksisting, dan kinerja dari instalasi pengolah lindi dan mengoptimalisasi instalasi pengolah lindi TPAS Simpang Kandis Kabupaten Ogan Komering Ulu. Hasil yang didapatkan kondisi sampah dan air lindi TPAS Simpang Kandis Kabupaten Ogan Komering sudah melebihi dinding geotekstil. Pipa yang di rancang untuk kepermukaan tidak semuanya muncul di permukaan. Penimbunan tanah, waktu dan tinggi atau volume sampahnya tidak sesuai dengan Standar Operational yang sudah direncanakan.
\end{abstract}

Kata Kunci : Air lindi, Instalasi Pengolahan, Tempat Pembuangan Akhir Sampah

\begin{abstract}
Leachate is water with a high concentration of organic content is formed in landfills due to rainwater entering the landfill. This liquid is very dangerous because in addition to its high organic content, it can also contain metal elements (such as $\mathrm{Zn}, \mathrm{Hg}$ ). Every day the volume of waste produced in Ogan Komering Ulu Regency reaches around $180 \mathrm{~m} 3$ per day or waste reaches 50 tonnes/day. The leachate produced in the tubing is more abundant and more abundant when it rains continuously. The increasing number of waste generation every day will affect the performance of the leachate drainage installation, and affect the storage of leachate discharge produced from TPAS Simpang Kandis, Ogan Komering Ulu Regency. The research objective was to evaluate the leachate treatment plant at the Simpang Kandis TPAS, Ogan Komering Ulu Regency. Data processing and analysis carried out is to calculate the amount of leachate discharge generated from TPAS Simpang Kandis, by taking direct measurements and calculating the leachate discharge using rational methods, evaluating the conditions of the existing leachate processing plant, and the performance of the leachate processing installation and optimizing the leachate processing installation TPAS Simpang Kandis, Ogan Komering Ulu Regency. The results obtained were the conditions of garbage and leachate at TPAS Simpang Kandis, Ogan Komering Ulu Regency, which had exceeded the geotextile wall. Pipes that are designed for the surface do not all appear on the surface. Landfill, time and height or volume of waste are not in accordance with the planned Operational Standards.
\end{abstract}

Keywords : Leachate, Processing Plan, Final Waste Disposal Site 


\section{PENDAHULUAN}

Lindi adalah limbah cair sebagai akibat masuknya air eksternal ke dalam timbunan limbah/sampah kemudian membilas dan melarutkan materi yang ada dalam timbunan tersebut, sehingga memiliki variasi kandungan polutan organik dan anorganik. Instalasi pengolahan limbah lindi adalah instalasi yang memproses limbah lindi agar bila dibuang ke sungai tidak mencemari lingkungan.Dampak negatif air lindi adalah dapat membunuh biota-biota yang ada di sungai,pencemaran air tanah, terutama di daerah yang curah hujan dan muka air tanahnya tinggi. (Saleh, C dan Purnomo H, 2014). Air lindi (Leachate) adalah air dengan kandungan organik yang berkonsentrasi tinggi, terbentuk di dalam landfill yang diakibatkan adanya air hujan yang masuk ke dalam landfill. Cairan air ini sangat berbahaya, selain mempunyai kandungan organik yang tinggi, caian ini juga mengandung unsur logam (seperti $\mathrm{Zn}, \mathrm{Hg}$ ). Jika tidak diatasi dengan benar, tanah sekitar landfill dapat menyerap air lindi dan mencemari air tanah yang ada di sekitar landfill (Abrauw, 2019). Limbah yang dibuang di tempat pembuangan sampah dapat menimbulkan beberapa risiko kesehatan masyarakat dan lingkungan termasuk pencemaran air tanah, logam berat pencemaran di dalam tanah, serta produksi emisi gas rumah kaca dan volatil senyawa organik (VOC). Pencemaran air tanah dan air permukaan di perkotaan di negara berpenghasilan rendah dengan polutan organik, anorganik dan mikroba karena kontaminasi dari lindi adalah masalah umum dan signifikan (Vaccari, etl, 2018).

Faktor-faktor yang mempengaruhi air lindi diantaranya adalah jenis sampah yang ada, komposisi sampah, ukuran partikel tanah, tingkat pemadatan tanah, hidrologi, iklim, usia TPA dan lokasi TPAS itu sendiri. Pengolahan limbah lindi harus dilakukan dengan cara (teknik) dan sistem yang tepat, sehingga tidak berdampak pada pencemaran limbah beracun dan berbahaya bagi lingkungannya. Karakteristik air lindi pada proses pengolahan air limbah cairnya di TPAS harus selalu dipantau terutama pada pada operasional Instalasi Pengolahan Air Limbah (IPAL) TPAS, sehingga dapat mengurangi dampak pencemaran lingkungan pada wilayah TPAS. Air lindi dapat merembes melalui tanah dan dimungkinkan pula akan mencemari air tanah yang ada di lokasi Tempat Pembuangan Akhir (TPA). Perembesan ini sangat tergantung dari sifat fisik tanah dasar TPA seperti porositas, permeabilitas dan tekanan piezometrik. Air lindi akan merembes melalui tanah secara perlahan. Apabila terdapat aliran air tanah di bawah lokasi TPA, maka air lindi akan mencemari aliran tersebut dengan kandungan zat yang cukup berbahaya bagi lingkungan (Alfiandy dalam Saleh \& Purnomo, 2014).

Wijaya (2018) dalam penelitiannya merencanakan suatu Tempat Pemrosesan Akhir (TPA) Blandongan yang dapat melayani 4 wilayah kecamatan di Kota Pasuruan, dengan dimensi ukuran kolam lindi 8 × 8 x 5 meter, dimensi kolam stabilisasi 18 x 9 × 12,5 meter, dimensi kolam aerasi $10 \times 10 \times 2$ meter dan dimensi kolam pematangan $19 \times 9,5 \times 1,5$ meter yang dapat menampung produl lindi sebanyak 95,95 mm. Dimana selama ini di TPA Blandongan dilakukan dengan metode sanitary landfill (metode pengurugan), sehingga menyebabkan terkontaminasinya tanah oleh air lindi

Tempat Pembuangan Akhir Sampah (TPAS) Simpang Kandis Adalah salah satu tempat pembuangan akhir sampah terbesar di Kabupaten Ogan Komering Ulu (OKU). Luas lahan yang di pakai untuk tempat pembuangan akhir sampah (TPAS) Simpang 
Kandis Kabupaten OKU seluas 33 hektar dari sejak mulai beroperasi pada tahun 2014 hingga sekarang. Setiap hari volume sampah yang dihasilkan di Kabupaten Ogan Komering Ulu mencapai sekitar $180 \mathrm{~m}^{3}$ perhari atau sampah mencapai 50 ton/harinya (Dinas Lingkungan Hidup Kabupaten OKU, 2019). Setiap tahunnya sampah yang di hasilkan semakin meningkat sesuai perkembangan penduduk setempat. Sampah yang setiap hari bertambah dan menumpuk di tempat lokasi pembuangan akhir sampah menyebabkan bau yang tidak sedap dan air lindi yang dihasilkan pun semakin banyak (Pichtel, J, 2005). Air lindi yang di hasilkan di bak penambungan semakin banyak dan berlimpah ditambah lagi bila hujan terjadi terus menerus. Air lindi keluar dari bak penampungan mengalir ke tanah di sekitar lokasi sehingga berdampak kepada kondisi disekitar lokasi terutama ke sumur-sumur masyarakat. Semakin bertambah timbuan sampah di setiap harinya akan mempengaruhi kinerja instalasi saluran air lindi, dan berpengaruh terhadap penampungan debit air lindi yang dihasilkan dari TPAS Simpang Kandis Kabupaten OKU sehingga perlu dilakukan evaluasi terhadap instalasi air lindi apakah masih layak untuk digunakan atau perlu dilakukan perencanaan baru instalasi pengolahan air lindi.

Dari latar belakang di atas maka tujuan penelitian ini adalah untuk mengevaluasi instalasi pengolahan air lindi di tempat pembuangan akhir sampah (TPAS) Simpang Kandis Kabupaten Ogan Komering Ulu.

\section{METODE PENELITIAN}

Penelitian ini dilakukan di Tempat Pembuangan Akhir Sampah (TPAS) Simpang Kandis Kabupaten Ogan Komering Ulu. Metode yang dilakukan adalah pengamatan langsung di lapangan melalui pengukuran-pengukuran debit air lindi, kondisi instalasi tempat pengolahan air lindi dan kinerja instalasi pengolahan air lindi tersebut. Data yang diperlukan terdiri dari data primer berupa data eksisting, data debit primer lindi dan data sekunder berupa data administratif, kependudukan, kondisi prasarana dan sarana eksisting pengolahan sampah TPAS Simpang Kandis Kabupaten Ogan Komering Ulu. Pengambilan data primer ini dilakukan dengan mengukur dimensi kolam, mengukur debit lindi dan mengukur data tinggi muka air. Pengolahan dan analisis data dilakukan dengan menghitung besarnya debit lindi yang dihasilkan dari TPAS, yaitu dengan pengukuran secara langsung serta penghitungan debit lindi dengan metode rasional, kemudian mengevaluasi kondisi instalasi pengolah lindi eksisting, dan kinerja dari instalasi pengolah lindi, serta mengoptimalisasi instalasi pengolah lindi TPAS Simpang Kandis Kabupaten Ogan Komering Ulu

\section{HASIL DAN PEMBAHASAN}

Lokasi Tempat Pembuangan Akhir Sampah (TPAS) Simpang Kandis Kabupaten OKU kondisinya tidak sesuai dengan perencanaan awal. Kondisi yang terjadi saat ini adalah air lindi tidak semuanya masuk ke instalasi perpipaan hingga ke bak penampungan. Hal ini dikarenakan berlapis-lapisnya timbunan tanah sehingga instalasi perpipaanya tidak semuanya sampai ke permukaan. Sampah dan timbunan sudah melebihi ketinggian 
geotekstil yang ada sehingga air lindi tumpah ke permukaan tanah disekeliling lokasi.Perencanaan awal peta zona TPAS Simpang Kandis Kabupaten OKU.

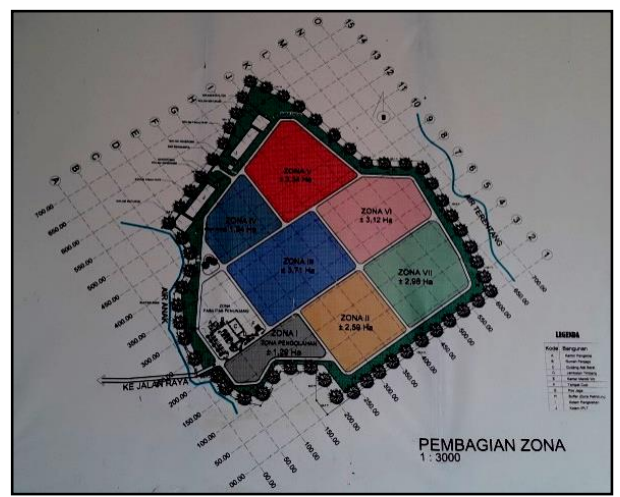

Gambar 1. Perencanaan awal Peta Zona TPAS Simpang Kandis

Pada instalasi existing terlihat bahwa pipa yang berfungsi untuk instalasi pengaliran air lindi ada 7 pipa dari 13 pipa yang ada, itupun dalam kondisi pipa yang tertumpuk oleh sampah di landfill. Salah satu penyebab air lindi tidak semuanya masuk ke instalasi perpipaan adalah kondisi pipa yang tidak baik dan tidak tidak terawat di lokasi landfill, sehingga air lindi yang seharusnya mengalir di pipa tidak teralirkan dengan baik, air lindi justru mengalir ke tanah disekitar lokasi dan bahkan diperkebunan milik penduduk. Instalasi existing dapat dilihat pada gambar 1. Kolam penampungan berjumlah 13 kolam dengan kondisi kolam sebagai berikut:

a. Kolam 1 dengan panjang $5 \mathrm{~m}$, lebar $4 \mathrm{~m}$ dan kedalaman mencapai $3 \mathrm{~m}$. Kolam 1 ini sebagai tempat atau wadah air lindi pertama dari sampah yang terbilas air hingga mengalir ke perpipaan dalam ladfil. Kolam 1 penuh dengan material seperti pasir, kerikil dan lumpur. Ada buah pintu buka tutup untuk mengatur pengendalian air dari kolam satu ke kolam dua.

b. Kolam 2 dengan panjang 7,5 $\mathrm{m}$ dan lebar $4 \mathrm{~m}$ dan kedalaman mencapai $3 \mathrm{~m}$. Kolam 2 ini sebagai tempat atau wadah air lindi kedua merupakan limpahan dari kolam 1 dengan tinggi air lindi mencapai $130 \mathrm{~cm}$ air lindi, tinggi lumpur $70 \mathrm{~cm}$.

c. Kolam 3 dengan panjang 7,5 $\mathrm{m}$ dan lebar $4 \mathrm{~m}$ dan kedalaman mencapai $3 \mathrm{~m}$. Dimana kolam 3 ini sebagai tempat atau wadah air lindi kedua limpahan dari kolam 2 dengan tinggi air lindi mencapai $140 \mathrm{~cm}$ air lindi, tinggi lumpur $60 \mathrm{~cm}$.

d. Kolam 4 dengan panjang 7,5 $\mathrm{m}$ dan lebar $4 \mathrm{~m}$ dan kedalaman mencapai $3 \mathrm{~m}$. Kolam 4 ini sebagai tempat atau wadah air lindi ke 4 limpahan dari kolam 3 dengan tinggi air lindi mencapai $140 \mathrm{~cm}$ air lindi, tinggi lumpur $60 \mathrm{~cm}$.

e. Kolam 5 dengan panjang 7,5 $\mathrm{m}$ dan lebar $4 \mathrm{~m}$ dan kedalaman mencapai $3 \mathrm{~m}$. Kolam 5 ini sebagai tempat atau wadah air lindi ke 5 limpahan dari kolam 4 dengan tinggi air lindi mencapai $140 \mathrm{~cm}$ air lindi, tinggi lumpur $60 \mathrm{~cm}$.

f. Kolam 6 dengan panjang 7,5 $\mathrm{m}$ dan lebar $4 \mathrm{~m}$ dan kedalaman mencapai $3 \mathrm{~m}$. Kolam 6 ini sebagai tempat atau wadah air lindi ke 6 limpahan dari kolam 5 dengan tinggi air lindi mencapai $150 \mathrm{~cm}$ air lindi, tinggi lumpur $50 \mathrm{~cm}$. 
g. Kolam 7 dengan panjang 7,5 $\mathrm{m}$ dan lebar $4 \mathrm{~m}$ dan kedalaman mencapai $3 \mathrm{~m}$. Kolam 7 ini sebagai tempat atau wadah air lindi ke 7 limpahan dari kolam 6 dengan tinggi air lindi mencapai $150 \mathrm{~cm}$ air lindi, tinggi lumpur $50 \mathrm{~cm}$.

h. Kolam 8 dengan panjang 7,5 $\mathrm{m}$ dan lebar $4 \mathrm{~m}$ dan kedalaman mencapai $3 \mathrm{~m}$. Kolam 8 ini sebagai tempat atau wadah air lindi ke 8 limpahan dari kolam 7 dengan tinggi air lindi mencapai $150 \mathrm{~cm}$ air lindi, tinggi lumpur $50 \mathrm{~cm}$.

i. Kolam 9 dengan panjang 7,5 $\mathrm{m}$ dan lebar $4 \mathrm{~m}$ dan kedalaman mencapai $3 \mathrm{~m}$. Kolam 9 ini sebagai tempat atau wadah air lindi ke 9 limpahan dari kolam 8 dengan tinggi air lindi mencapai $150 \mathrm{~cm}$ air lindi, tinggi lumpur $50 \mathrm{~cm}$. Disediakan dua buah pintu buka tutup untuk mengendalikan arus air lindi dari kolam sembilan ke kolam penyaring hingga ke kolam sepuluh.Dengan kolam tertutup panjang 3 meter persegi dan ada lubang kecil berukuran $14 \mathrm{~cm}$ di tengah-tengah.

j. Kolam 10 dengan panjang $15 \mathrm{~m}$ dan lebar $5 \mathrm{~m}$ dan kedalaman mencapai $3 \mathrm{~m}$. Kolam 10 ini sebagai tempat atau wadah air lindi 10 limpahan dari kolam 9 dengan tinggi air lindi mencapai $240 \mathrm{~cm}$, tinggi lumpur $160 \mathrm{~cm}$.

k. Kolam 11 dengan panjang $15 \mathrm{~m}$ dan lebar $5 \mathrm{~m}$ dan kedalaman mencapai $3 \mathrm{~m}$. Kolam 11 ini sebagai tempat atau wadah air lindi ke 11 limpahan dari kolam X (sepuluh) dengan tinggi air lindi mencapai $240 \mathrm{~cm}$ air lindi, tinggi lumpur $160 \mathrm{~cm}$.

1. Kolam 12 dengan panjang $15 \mathrm{~m}$ dan lebar $6 \mathrm{~m}$ dan kedalaman mencapai $6 \mathrm{~m}$. Kolam 12 ini sebagai tempat atau wadah air lindi ke 12 limpahan dari kolam 11 dengan tinggi air lindi mencapai $250 \mathrm{~cm}$. Tinggi lumpur $150 \mathrm{~cm}$.

m. Kolam 13 dengan panjang $5 \mathrm{~m}$ dan lebar $5 \mathrm{~m}$ dan kedalaman mencapai $3 \mathrm{~m}$. Kolam 13 ini sebagai tempat atau wadah yang isinya hanya ada tanah atau lumpur kering.

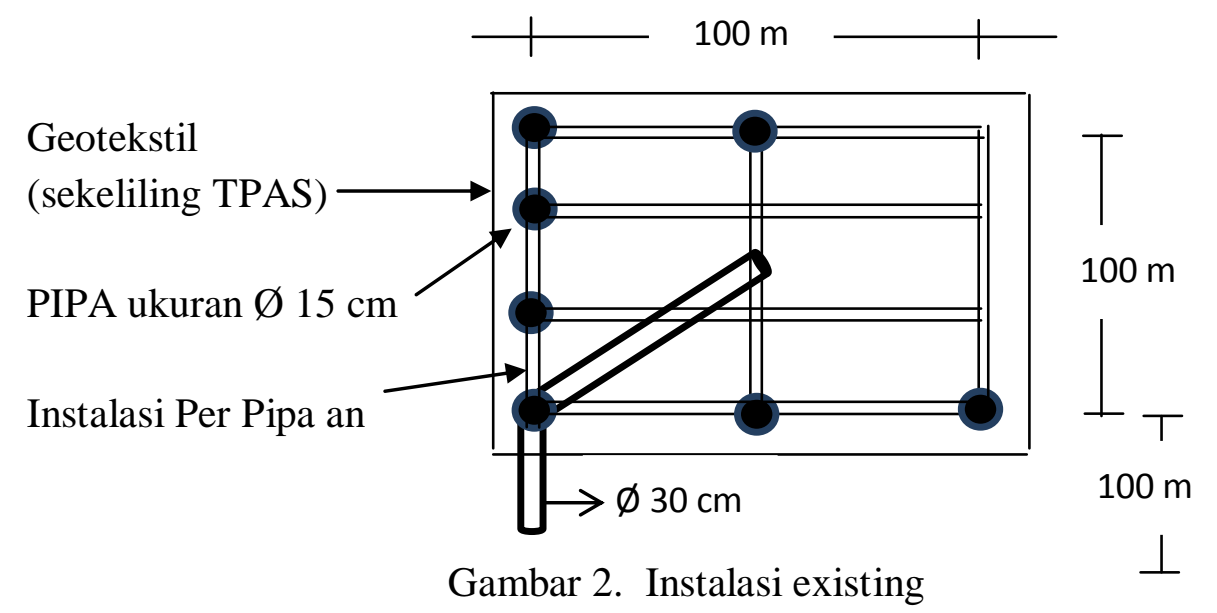

Instalasi hasil dibuat dengan menambahkan perpipaan sampai ke permukaan dan geotektil di sekeliling landfill. Ini adalah upaya agar air lindi masuk ke instalasi yang sudah direncanakan dan tidak tumpah ke tanah atau ke perkebunan masyarakat sekitar landfill. Selain itu pembenahan siring pasang yang sudah ada sehingga air lindi mengalir ditempat seharusnya. Detail instalasi dari perpipaan landfill hingga sampai ke perkolamam air lindi yang digunakan adalah luas landfill 100 m x 100 m dan ukuran pipa dalam landfill yang digunakan $\varnothing 15 \mathrm{~cm}$. Ukuran pipa yang di gunakan untuk mengalirkan air lindi dari landfill ke perkolaman adalah $\emptyset 30 \mathrm{~cm}$. Landfill di batasi dengan pemakaian 
dinding geotekstil agar mencegah terjadinya resapan air lindi meluas ke sekitaran landfill. Pintu air lindi di biarkan terbuka, dan tidak ada lagi pengaturan buka tutup pintu air lindi. Instalasi hasil dapat dilihat pada Gambar 2.

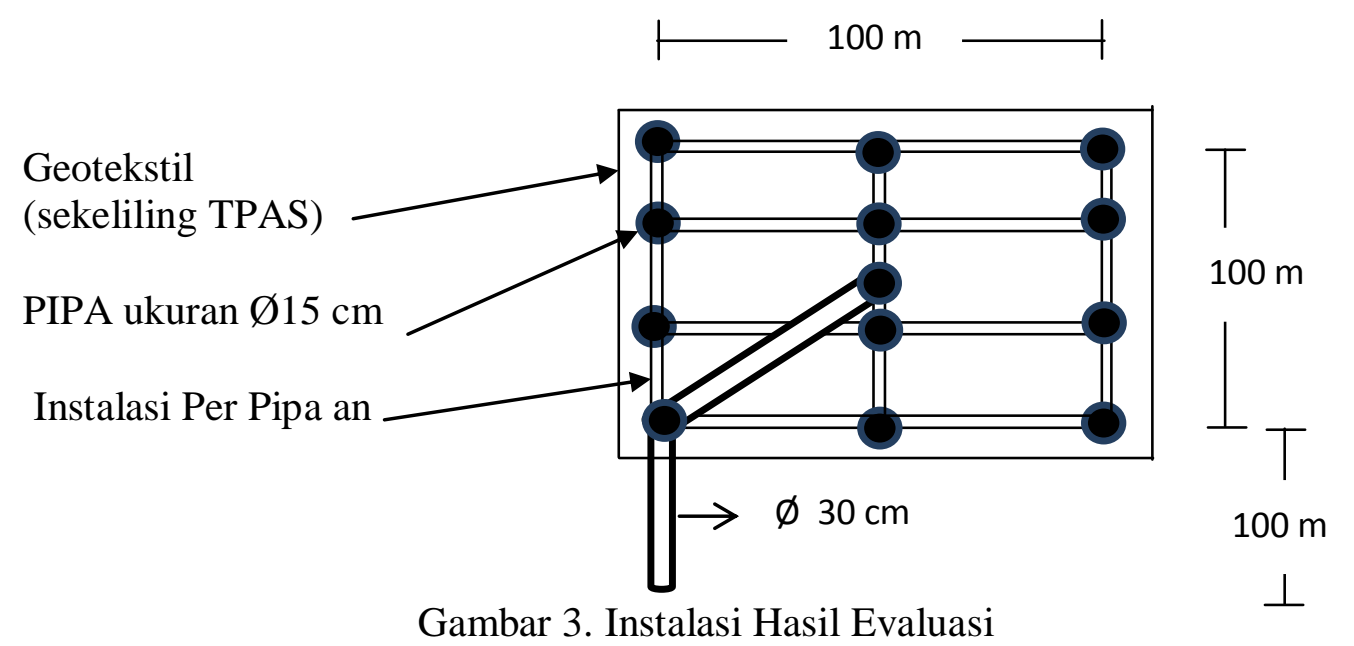

Sistem perpipaan air lindi di dalam landfill terdiri dari pipa primer dan pipa sekunder yang di lubangi dengan diameter $2 \mathrm{~cm}$. Pipa primer berdiameter $30 \mathrm{~cm}$ dan pipa sekunder berdiameter $15 \mathrm{~cm}$ yang di rancang atau disambungkan satu sama lain dan di bungkus oleh drum berbahan plastik yang di lubangi dengan diameter $2 \mathrm{~cm}$. Pipa sekunder yang tersambung ke pipa primer hingga tersambung ke kolam penampungan. Geotekstil adalah alat yang berpungsi sebagai dinding pembatas antara landfill dan lahan sekitar agar air lindi tidak meresap ketanah sekitar landfill. Geotekstil di pasang disekeliling area landfill untuk memastikan air lindi tidak menjalar ke lahan masyarakat sekitar area landfill. Perpipaan air lindi dan pengaturan kolam air lindi dapat dilihat pada Gambar 3.

Perhitungan debit air lindi di kolam 1 sebagai penerima pertama aliran air lindi dengan panjang $5 \mathrm{~m}$ dan lebar $4 \mathrm{~m}$ dan kedalaman $3 \mathrm{~m}$. Di kolam satu banyak koral pasir dan lumpur serta sampah-sampah yang lebih kecil dari lubang penyaringan dengan ukuran tinggi $210 \mathrm{~cm}$ endapan lumpur dan $10 \mathrm{~cm}$ air lindi. Debit aliran air lindi maksimum terdapat di kolam 12 yaitu 40 liter selama 20 menit, debit air yang mengalir dari landfill ke kolam 12 tersebut adalah $66,67 \mathrm{~m}^{3} /$ detik.

Diketahui :

Volume $(\mathrm{A})=40$ liter $=40.000 \mathrm{~m}^{3}$

Waktu (t) $=20$ menit $=600$ detik

Penyelesaian

$$
\mathrm{Q}=\mathrm{V} / \mathrm{t} \text {---- }>\mathrm{Q}=40.000 / 600=66,67 \mathrm{~m}^{3} / \mathrm{detik}
$$

Kolam 12 memiliki ukuran panjang 15 m, lebar 6 m, kedalaman 6 m. Kolam ke 12 ini adalah kolam terakhir yang di aliri air lindi dan penampungan terbesar di antara kolam yang lain. Tinggi lumpur mencapai $150 \mathrm{~cm}$, tinggi air lindi $250 \mathrm{~cm}$. Air lindi yang dihasilkan di kolam 12 merupakan aliran dari kolam 11 dengan menggunakan 3 buah pipa, diantaranya berada di sisi kiri di tengah dan di sisi kanan. Air lindi mengalir melalui drainase yang di rancang seperti air terjun natural sehingga tidak menggunakan perpipaan lagi. 


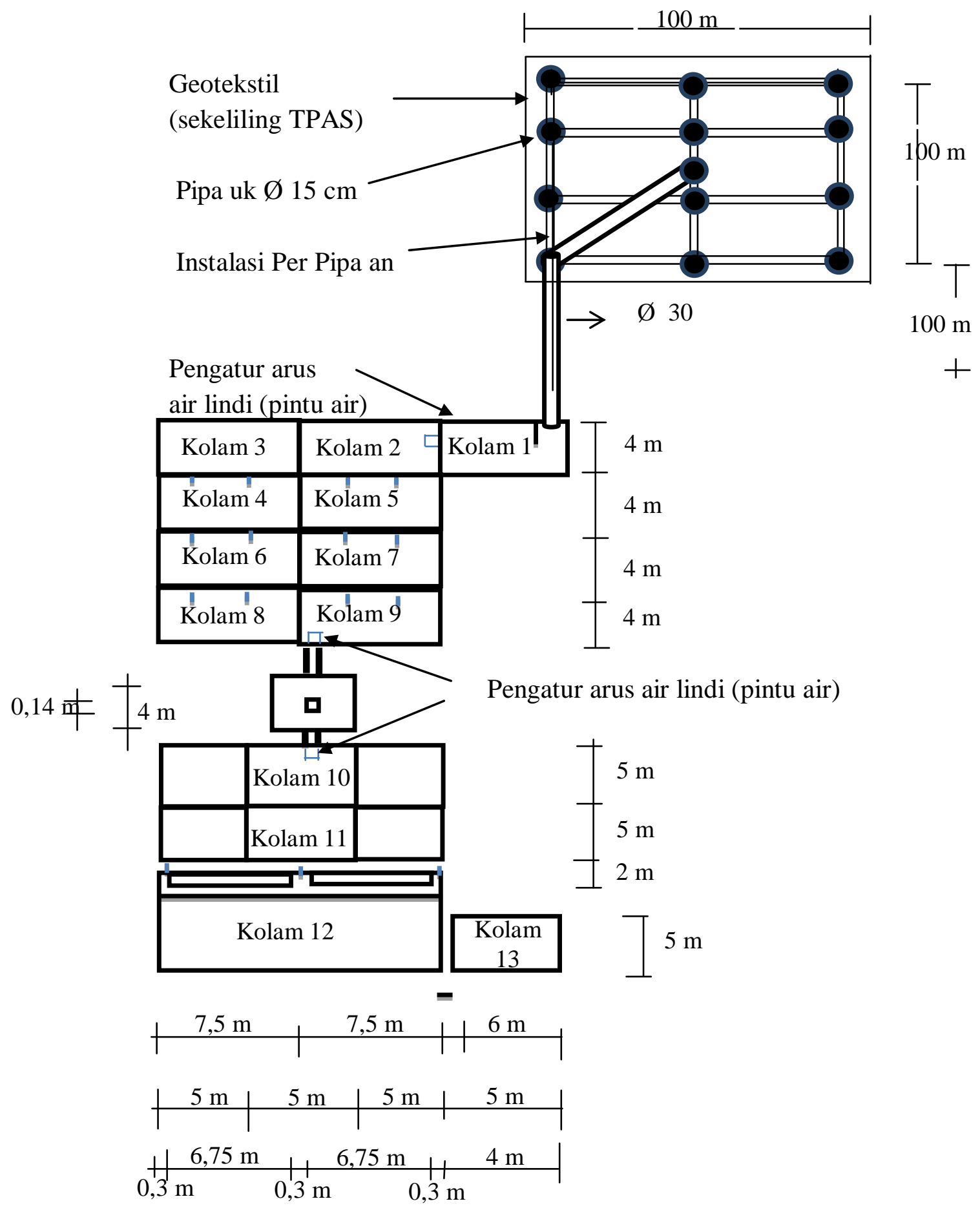

Gambar 4. Sistem perpipaan dan kolam penampungan air lindi

Perhitungan debit air lindi di kolam 1 sebagai penerima pertama aliran air lindi dengan panjang $5 \mathrm{~m}$ dan lebar $4 \mathrm{~m}$ dan kedalaman $3 \mathrm{~m}$. Di kolam satu banyak koral pasir dan lumpur serta sampah-sampah yang lebih kecil dari lubang penyaringan dengan ukuran tinggi $210 \mathrm{~cm}$ endapan lumpur dan $10 \mathrm{~cm}$ air lindi. Debit Aliran air lindi maksimum terdapat di kolam 12 yaitu 40 liter selama 20 menit, debit air yang mengalir dari landfill ke kolam 12 tersebut adalah $66,67 \mathrm{~m}^{3} /$ detik. 
Diketahui :

Volume $(\mathrm{A})=40$ liter $=40.000 \mathrm{~m}^{3}$

Waktu $(\mathrm{t}) \quad=20$ menit $=600$ detik

Penyelesaian

$$
\mathrm{Q}=\mathrm{V} / \mathrm{t}---->\mathrm{Q}=40.000 / 600=66,67 \mathrm{~m}^{3} / \mathrm{detik}
$$

Kolam 12 memiliki ukuran panjang 15 m, lebar 6 m, kedalaman 6 m. Kolam ke 12 ini adalah kolam terakhir yang di aliri air lindi dan penampungan terbesar di antara kolam yang lain. Tinggi lumpur mencapai $150 \mathrm{~cm}$, tinggi air lindi $250 \mathrm{~cm}$. Air lindi yang dihasilkan di kolam 12 merupakan aliran dari kolam 11 dengan menggunakan 3 buah pipa, diantaranya berada di sisi kiri di tengah dan di sisi kanan. Air lindi mengalir melalui drainase yang di rancang seperti air terjun natural sehingga tidak menggunakan perpipaan lagi.

Proses bekerjanya instalasi aliran air lindi ini adalah bermula dari air hujan yang membilas tumpukan sampah yang secara alami mengalami permentasi dan pembusukan yang kemudian air lindi tersebut masuk ke saluran perpipaan. Dari saluran perpipaaan sekunder mengalir ke perpipaan primer, dimana saluran ini lebih besar dari saluran sekunder yang menghubungkan dari seluruh pipa sekunder ke perkolaman. Bentuk di dalam landfill dirancang sedemikian rupa agar air lindi bisa mengalir dari tempat tinggi ke tempat lebih rendah. Di buat seperti segitiga terbalik sehingga air lindi bisa mengalir dan mudah meresap. Di dalam landfill juga di pasang geotektil dan plastik hingga bangunan beton, di bangun agar air lindi tidak meresap keluar landfill sehingga air lindi bisa meresap dan mengalir ke saluran perpipaan hingga ke perkolaman.

Keunggulan instalasi perpipaan pada pengelolan air lindi yaitu pada pipa yang sudah di rancang dari perencanaan awal sangat bagus, karena memudahkan air lindi mengalir dan meresap dan diarahkan untuk mengalirkannya ke perpipaan hingga ke perkolaman. Kelemahan instalasi perpipaan adalah kondisi pipa yang terbuat dari bahan plastik yang tidak bisa menahan panas dengan panas tertentu. Jika pipa mengalami pemanasan maka pipa akan meleleh dengan panas tertentu. Jika dalam keadaan dingin maka akan mengalami pelicinan. Pipa akan mengalami timbal sehingga pipa akan rusak dengan berjalan nya waktu atau pipa mudah patah dan pecah apa lagi ketika alat berat yang di gunakan untuk bekerja merapihkan, meratakan, atau menyusun sampah dan menimbun sampah. Ketika pipanya patah atau pecah di akibatkan tersenggol alat berat tersebut maka pipa harus cepat di sambung atau di ganti yang baru.

\section{KESIMPULAN}

Kondisi sampah dan air lindi di empat pembuangan akhir sampah (TPAS) Simpang Kandis Kabupaten Ogan Komering Ulu sudah melebihi dinding geotekstil. Pipa yang di rancang untuk kepermukaan tidak semuanya muncul di permukaan. Penimbunan tanah, waktu dan tinggi atau volume sampahnya tidak sesuai dengan SOP yang sudah direncanakan. 


\section{DAFTAR PUSTAKA}

Abrauw, A. E. S. (2019). Studi Operasional Pengelolaan Limbah Cair Lindi (Leachet) pada TPA Control Landfill Koya Koso. DINAMIS, 16(1, Juli), 1-10.

Dinas Lingkungan Hidup Kabupaten OKU. 2019.

Pichtel, J. 2005. Waste, Its Origin, Its Destination. Amerika Serikat: CRC Press

Saleh, C., \& Purnomo, H. (2014). Analisis Efektifitas Instalasi Pengolahan Limbah Lindi Di TPA Supit Urang Kota Malang. Jurnal Teknik Pengairan: Journal of Water Resources Engineering, 5(1), 103-109.

Vaccari, M., Vinti, G., \& Tudor, T. (2018). An analysis of the risk posed by leachate from dumpsites in developing countries. Environments, 5(9), 99.

Wijaya, F. A. (2018). Studi Perencanaan Instalasi Pengolahan Limbah Lindi Pada TPA Blandongan Kota Pasuruan (Doctoral dissertation, University of Muhammadiyah Malang). 